\title{
Epidermal Growth Factor Receptor Gene-Amplified MDA-468 Breast Cancer Cell Line and Its Nonamplified Variants
}

\author{
JORGE FILMUS, ${ }^{1}$ JEFFREY M. TRENT, ${ }^{2}$ MICHAEL N. POLLAK, ${ }^{1 \dagger}+$ AND RONALD N. BUICK ${ }^{1 *}$ \\ Ontario Cancer Institute and Department of Medical Biophysics, University of Toronto, Toronto, Ontario, Canada M4X \\ 1K9, ${ }^{1}$ and University of Arizona Cancer Center, Tucson, Arizona 85724 ${ }^{2}$
}

\begin{abstract}
We have recently reported (J. Filmus, M. N. Pollak, R. Cailleau, and R. N. Buick, Biochem. Biophys. Res. Commun. 128:898-905, 1985) that MDA-468, a human breast cancer cell line with a high number of epidermal growth factor (EGF) receptors, has an amplified EGF receptor gene and is growth inhibited in vitro pharmacological doses of EGF. We have derived several MDA-468 clonal variants which are resistant to EGF-induced growth inhibition. These clones had a number of EGF receptors, similar to normal human fibroblasts, and had lost the EGF receptor gene amplification. Karyotype analysis showed that MDA-468 cells had an abnormally banded region (ABR) in chromosome $7 p$ which was not present in the variants. It was shown by in situ hybridization that the amplified EGF receptor sequences were located in that chromosome, 7pABR. Five of the six variants studied were able to generate tumors in nude mice, but their growth rate was significantly lower than that of tumors derived from the parental cell line. The variant that was unable to produce tumors was found to be uniquely dependent on EGF for growth in soft agar.
\end{abstract}

We have recently reported that MDA-468, a human breast cancer cell line, has an amplified epidermal growth factor receptor (EGFR) gene (3). Consequently these cells show a very high number of EGFR (approximately $1.5 \times 10^{6}$ receptors per cell). Despite the amplification, the EGFR from MDA-468 cells show characteristics similar to those of receptors from normal cells. The usual band of 170,000 daltons is detected by immunoprecipitation with EGFRspecific monoclonal antibodies (12), and the normal EGFR mRNA-related species have been found with Northern blot analysis (3). Also, as in other cell lines, incubation with epidermal growth factor (EGF) induces the downregulation of the EGFR (12).

Gene amplification and overexpression of the EGFR had been reported for different types of tumors $(8,9,14)$, and it has been proposed that increased expression of EGFR may confer a selective growth advantage under conditions of limiting EGF (5). To study the chromosomal basis for EGFR gene amplification in MDA-468 cells and the relationship of this amplification to in vivo growth, we have generated several clonal MDA-468 variants which have lost the EGFR gene amplification. For generation of the variants we took advantage of the fact that high EGF concentrations, which are mitogenic for a wide variety of cells in culture, induce growth inhibition in MDA-468 cells (3). Similar EGFinduced growth inhibition has been reported for a squamous carcinoma cell line (A431) (6), which also has a high number of EGFR as a consequence of gene amplification (18). Here we present a comparative study of the parental unselected MDA-468 cells and six randomly chosen variants.

\section{MATERIALS AND METHODS}

Cell culture. The MDA-468 cell line was derived from a human breast carcinoma (19). It was routinely cultured in L-15 medium supplemented with $10 \%$ fetal calf serum (FCS)

\footnotetext{
* Corresponding author.

† Present address: Department of Medicine, McGill University, and Division of Oncology, Sir Mortimer Davis Jewish General Hospital, Montreal, Quebec, Canada.
}

and passaged by trypsinization. A human fibroblast cell line $(427 \mathrm{~N})$, derived from a skin biopsy of a normal individual, was kindly provided by R. A. Phillips and cultured in alpha medium supplemented with $10 \%$ FCS.

Isolation of MDA-468 variants. A total of $10^{7} \mathrm{MDA}-468$ cells were plated in several $10-\mathrm{cm}$ culture dishes and allowed to attach overnight before the addition of EGF $\left(10^{-7} \mathrm{M}\right)$. The EGF-containing medium was changed twice weekly. After 14 days, colonies were isolated by cloning rings, transferred to microwells, and subsequently propagated in L-15 medium with $10 \%$ FCS supplemented with $10^{-8}$ M EGF.

$\left[{ }^{125}\right.$ I]EGF-binding assay. Binding studies were carried out in triplicate on subconfluent cells grown on $35-\mathrm{mm}$ dishes as described previously (4).

Immunoprecipitation of the EGFR. Cells were labeled with $\left[{ }^{35} \mathrm{~S}\right]$ methionine for $16 \mathrm{~h}$, lysed, and immunoprecipitated as described previously (16). R1, a monoclonal antibody against the EGFR, was provided by $M$. Waterfield. Sodium dodecyl sulfate (SDS)-polyacrylamide gel electrophoresis on slab gels was carried out with the buffer system of Laemmli. Gels were dried under vacuum and exposed to a film at $-70^{\circ} \mathrm{C}$.

DNA isolation and blotting. High-molecular-weight genomic DNA was isolated by SDS-proteinase $K$ lysis, organic extraction, and $\mathrm{NaCl}$-ethanol precipitation (7). DNA was digested with HindIII, electrophoresed in $0.8 \%$ agarose gels, and transferred to a Zetabind membrane (21). Hybridizations and washings were performed under high-stringency conditions. Probe-related nonspecific background was reduced as described elsewhere (26).

A cDNA clone ( $\mathrm{pE} 7$ ), isolated and provided by G. Merlino et al. (18), was used. It encodes a portion of the EGFR gene and is highly homologous to a portion of the v-erbB oncogene. The probe was ${ }^{32} \mathrm{P}$ nick-translated as described previously (20).

RNA isolation and blotting. Total RNA was isolated by guanidine isothiocyanate solubilization and centrifugation over a CsCl cushion. Polyadenylated [poly $(\mathrm{A})^{+}$] RNA $(4 \mu \mathrm{g})$ purified by passage over oligo(dT)-cellulose, was denatured with glyoxal and dimethyl sulfoxide, and electrophoresis 
TABLE 1. Estimates of $\left[{ }^{125} \mathrm{I}\right] \mathrm{EGF}-$ binding sites per cell

\begin{tabular}{|c|c|}
\hline Cell line & $\begin{array}{l}\text { No. of } \\
\text { binding } \\
\text { sites/cell }\end{array}$ \\
\hline $\begin{array}{l}\text { MDA-468 } \\
\text { S1 } \ldots \ldots \\
\text { S4 } \ldots \ldots \\
\text { S5 } \ldots \ldots \\
\text { S10 } \ldots \ldots \\
\text { S } 11 \ldots \ldots \\
\text { S12 } \ldots \ldots \\
427-N \ldots\end{array}$ & $\begin{array}{l}1.5 \times 10^{6} \\
1.6 \times 10^{4} \\
3.3 \times 10^{4} \\
1.8 \times 10^{4} \\
4.2 \times 10^{4} \\
6.6 \times 10^{4} \\
3.8 \times 10^{4} \\
5.1 \times 10^{4}\end{array}$ \\
\hline
\end{tabular}

was performed in a $1.1 \%$ agarose gel. The RNA was then transferred to a Zetabind filter (23) and hybridized under high-stringency conditions.

Efiect of EGF on growth in plastic-adherent cultures. A total of $10^{4}$ cells were plated in triplicate in $35-\mathrm{mm}$ plates containing L-15 medium supplemented with $10 \%$ FCS and allowed to attach overnight, after which various concentrations of EGF were added. Cells were incubated at $37^{\circ} \mathrm{C}$ for 7 days, with medium changes every $48 \mathrm{~h}$. The cells were then trypsinized and counted by hemacytometer.

Effect of EGF on growth in soft agar cultures. A total of $10^{4}$ cells were plated in triplicate in $35-\mathrm{mm}$ plates in a two-layer system of agar $(0.3 \%, \mathrm{wt} / \mathrm{vol})$ on agar $(0.5 \%, \mathrm{wt} / \mathrm{vol})$ in $\mathrm{L}-15$ medium supplemented with $10 \%$ FCS and various concentrations of EGF. Cells were incubated at $37^{\circ} \mathrm{C}$, and colony counts were performed after 3 weeks, with $\geq 60$ cells designated a clonal unit.

In vivo growth. To compare the tumorigenicity of the parental MDA- 468 cells and the variants, $5 \times 10^{6}$ cells were injected subcutaneously in female nude mice (5 to 6 weeks old). Five mice were used for each cell line. After 9 weeks, mice were sacrificed and the tumors were excised and weighed. For measurement of growth rate, $10^{7}$ cells were injected subcutaneously in nude mice; seven mice were used for each cell line. The diameters of tumors were measured with a caliper every 6 days, starting 14 days after the injection. Tumor volume was estimated by the formula $V=$ $L \times W^{2} \times 0.5$, where $V$ is volume, $L$ is length, and $W$ is width. Estimates of tumor volume were plotted versus days after inoculation, and the tumor doubling time was calculated from the resulting graph.

Karyology. Harvesting, slide preparation, and chromosome analysis with G- and C-banding techniques were performed as described previously (24). A minimum of 25 banded cells were analyzed per specimen, with results expressed by the International System of Human Cytogenic Nomenclature recommendations (10). In situ hybridization analysis was performed as described previously with a ${ }^{3} \mathrm{H}$-labeled $\mathrm{pE} 7$ probe $(25)$.

\section{RESULTS}

EGFR gene and its expression in MDA-468 and EGFresistant variants. The frequency of the appearance of clones resistant to EGF-induced growth inhibition in the MDA-468 line was approximately 1 in $10^{6}$ cells. Since our experiments were not initiated with a clonal population of MDA-468 cells, it was not possible to estimate the rate of generation of clonal variants in the parental line. Several clones were isolated in two different experiments and from different plates. Six of those clones were randomly chosen for this comparative study. All of them were similar in morphology to MDA-468 cells.
A [ ${ }^{125}$ I]EGF-binding assay was performed to estimate the number of EGFR in the different MDA-468 variants. All the variants lost the overexpression seen in parental unselected MDA-468 cells and had a number of EGFR, similar to normal human fibroblasts (Table 1). A number of other human breast cancer cell lines have been reported to express levels of receptors in the same range as the MDA-468 variants (3).

Immunoprecipitation of the EGFR from the MDA-468 variants was performed. Autoradiographs of SDSpolyacrylamide gels of the immunoprecipitates from the unselected MDA-468 line and a typical variant (S10) are shown in Fig. 1A. All the variants showed a 170-kilodalton (kDa) band, indicating that no major structural alterations occurred in the EGFR. The intensity of the EGFR band in the parental line and in the variants was consistent with the EGF-binding data.

To establish the relationship between the decreased number of EGFR in the variants and the EGFR gene amplification in unselected MDA-468 cells, a Southern blot analysis was performed with a cDNA probe for the EGFR gene (pE7). All the variants showed bands with intensities similar to those of normal human fibroblasts, indicating that they had lost the EGFR amplification. Figure 1B shows the hybridization pattern of a typical variant (S1), MDA-468 cells, and normal human fibroblasts. The degree of amplification of MDA- 468 cells was estimated to be approximately 20 -fold by scanning densitometry. An interesting feature of the hybridization pattern of the variants was the loss of a 4.9-kilobase band present not only in the parental tumor line but also in normal fibroblasts from the patient from whom the MDA-468 line was derived (3). The presence or absence

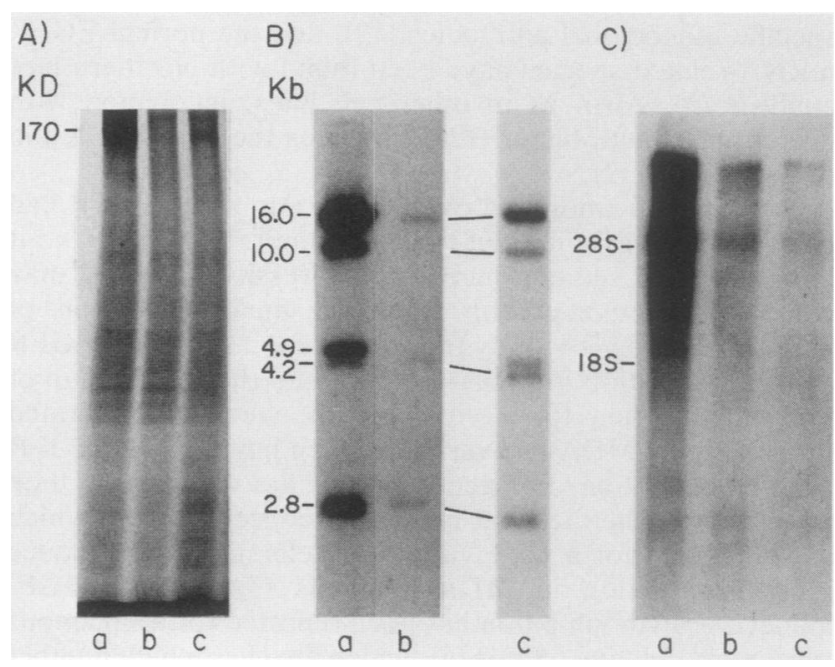

FIG. 1. Comparative analysis of EGFR. (A) Immunoprecipitation. A total of $10^{6}$ cells were labeled, lysed, and immunoprecipitated with R1, a monoclonal antibody against EGFR. The immunoprecipitates were run on SDS-polyacrylamide gel electrophoresis. Lanes: a, MDA-468; b, MDA-468 immunoprecipitated with nonspecific mouse immunoglobulin G IgG; c, S12. KD, Kilodalton. (B) Southern blots of 10 (lanes a and b) or $30 \mu \mathrm{g}$ (lane c) of DNA were digested, fractionated, transferred to a membrane, and hybridized with a cDNA probe for the EGFR gene (pE7). $\lambda$ DNA digested with HindIII was used as size markers. Lanes: a, MDA-468; b, S1; c, normal human fibroblasts. Kb, kilobases. (C) Northern blot. Poly $(\mathrm{A})^{+}$RNA (4 $\left.\mu \mathrm{g}\right)$ was denatured, fractionated, transferred to a membrane, and hybridized with pE7. Human $28 \mathrm{~S}$ and $18 \mathrm{~S}$ rRNAs were used as size markers. Lanes: a, MDA-468; b, S5; c, normal human fibroblasts. 
of that band in HindIII-restricted DNA from different normal individuals is probably the result of a restriction enzymespecific polymorphism $(3,17)$ and suggests that the variants all lost one of the alleles that codes for the EGFR gene. No differences in the hybridization banding pattern of the parental cells and the variants were detected when EcoRI or BamHI was used as the restriction enzymes (data not shown).

Figure 1C shows a Northern blot analysis for mRNA encoded by the EGFR gene in parental unselected MDA-468 cells, a typical variant (S5), and normal human fibroblasts. The intensity of the EGFR-related mRNA bands correlates with the results of the $\left[{ }^{125} \mathrm{I}\right] \mathrm{EGF}$-binding assay, the MDA-468 variants showing levels of expression similar to those of normal human fibroblasts. The variants express the same EGFR-related mRNA species as the parental cell line, 10.0 - and 5.6-kilobase species being the most prevalent transcripts. Scanning densitometry allowed us to estimate that these transcripts were approximately 30 -fold more abundant in the parental cell line.

Chromosomal basis for EGFR gene amplification in MDA-468 cells. To investigate the chromosomal basis for the EGFR gene amplification in MDA-468 cells and its loss in the variants, karyotypic analysis was performed. The detailed karyology of all the MDA-468 variants will be published elsewhere. A typical chromosome spread for MDA-468 is shown in Fig. 2. Of particular interest was the finding of an abnormally banded region (ABR) in MDA-468 cells, since ABRs have been associated with amplified chromosomal domains (1). The ABR was located in the short arm of chromosome 7, close to the reported location for the normal EGFR gene (17). The MDA-468 cells also showed two other alterations of chromosome 7: an isochromosome of the short arm [iso(7p)] and an unidentified translocation to $7 p(7 p+)$. The $7 p A B R$ was distinct from the $7 p+$ marker both by its banding pattern (Fig. 2, insert $p$ ) and by its centromere index (a reflection of the arm length ratio). Of importance to this study was the fact that although all cells from the parental cell line demonstrated the 7pABR marker, direct examination of all the variants failed to demonstrate the presence of the 7pABR marker (Fig. 2). In contrast, the $7 p+$ and the iso(7p) markers were found in all clones. In addition to the aforementioned alterations, most variants demonstrated identifiable alterations of chromosome 7 not found in the parental MDA-468 cell line [e.g., S10, $\operatorname{del}(7)(\mathrm{p} 11) ; \mathrm{S} 11$, iso(7q); $S 12, t(7 ; 11)$ (p11;q11)] (Fig. 2). In addition to structural alterations that could be identified, an unidentified translocation involving $7 p$ (differing from the $7 p A B R$ ) was recognized in two clones (S10 and S12, Fig. 2).

In situ hybridization was carried out to identify the chromosomal loci of amplified EGFR genes in the parental MDA-468 cell line. A final probe DNA concentration of 0.5 $\mu \mathrm{g} / \mathrm{ml}$ was used, with slides incubated for 14 days. To ensure correct identification of all chromosomes, cells were Qbanded and photographed prior to in situ hybridization. The total grain distribution to 53 cells was examined, with $25 \%$ (13 of 53) of all cells exhibiting one or more grains on the $7 \mathrm{pABR}$. Results revealed that $14 \%$ of all grains (19 of 139) were localized to the 7pABR chromosome, with $79 \%$ (15 of 19) of the grains localized to this marker residing along the ABR (Fig. 3). Label other than that observed on the 7pABR marker appeared to be distributed at random over the remaining chromosomes, with no significant binding to the $7 p+$ marker. Under the experimental conditions used, we were unable to detect the nonamplified locus of the EGFR gene.
Effect of EGFR gene amplification on growth in tissue culture and in vivo. The effect of EGF on the growth of the MDA-468 variants was studied. Under the serum-containing conditions used, all the variants showed a stimulation (between 5 and $48 \%$ at $10^{-9} \mathrm{M}$ EGF), whereas parental unselected MDA-468 cells were growth inhibited, as already shown (3). The results of a representative experiment including MDA-468 and variants S1 and S4 are presented in Fig. 4.

We also compared the effect of EGF on the proliferation of MDA-468 cells and the variants in soft agar. The MDA-468 line has a plating efficiency of approximately $5 \%$, and the variants displayed a range of plating efficiencies $(<0.01$ to $5 \%$ ). While anchorage-independent growth of MDA-468 was inhibited by EGF, all the variants were strongly stimulated, including S4, which was the only variant that did not grow at all in agar in the absence of added EGF. The dose response effect of EGF on the soft agar growth of MDA-468 cells and variant $\mathrm{S} 4$ is shown in Fig. 4 (inset).

Finally, we compared the in vivo tumorigenicity of the MDA-468 cells and the variants in nude mice. A total of $5 \times$ $10^{6}$ cells were injected subcutaneously, and 9 weeks later the mice were sacrificed and the tumors were excised and weighed. MDA- 468 cells and five of the six variants gave rise to progressively growing tumors. The tumors were assessed histopathologically and were classified as poorly differentiated adenocarcinomas. No significant differences could be seen between the tumors grown from parental unselected MDA-468 and the five subclones in terms of gross morphology or degree of normal cell infiltration. S4 was the only variant that did not produce any tumors, even 16 weeks after injection. The tumors generated by MDA-468 cells were significantly larger at 9 weeks of growth than the ones generated by the variants (Table 2 ). Repeat experiments at later times confirmed that these differences were a stable property of the variants (data not shown).

The growth rate of the parental line and four variants (S5, S10, S11, and S12) was also compared (S4 did not produce tumors and $\mathrm{S} 1$ grew very poorly). The growth rate of the parental unselected MDA-468 cells was significantly higher (Fig. 5). From the slope of the growth curve we estimate the doubling time of tumors generated by the parental line at 6 days, whereas the variants showed a doubling time of 9 to 10 days.

The six MDA-468 variants described in this paper have also proven to be very stable with respect to growth properties in culture, even when passaged without the addition of EGF. After being passaged for more than 1 year, no revertants have been found, and they still show resistance to the EGF-induced growth inhibition found in the parental MDA-468 cells. We confirmed this genetic stability after the generation of tumors in mice. When DNA extracted from tumors produced by MDA-468 cells and several variants was analyzed by Southern blot analysis, the intensity of hybridization with the EGFR gene probe pE7 was similar to the intensity detected in DNA from the cell lines used for the generation of the tumors (data not shown).

\section{DISCUSSION}

In this paper we have presented a comparative study on six clonal variants derived from a human breast cancer cell line which overexpresses EGFR as a consequence of gene amplification. The six variants show EGFR levels similar to normal human fibroblasts, have lost the EGFR amplification, and are resistant to the EGF-induced growth inhibition shown by the parental cell line. 


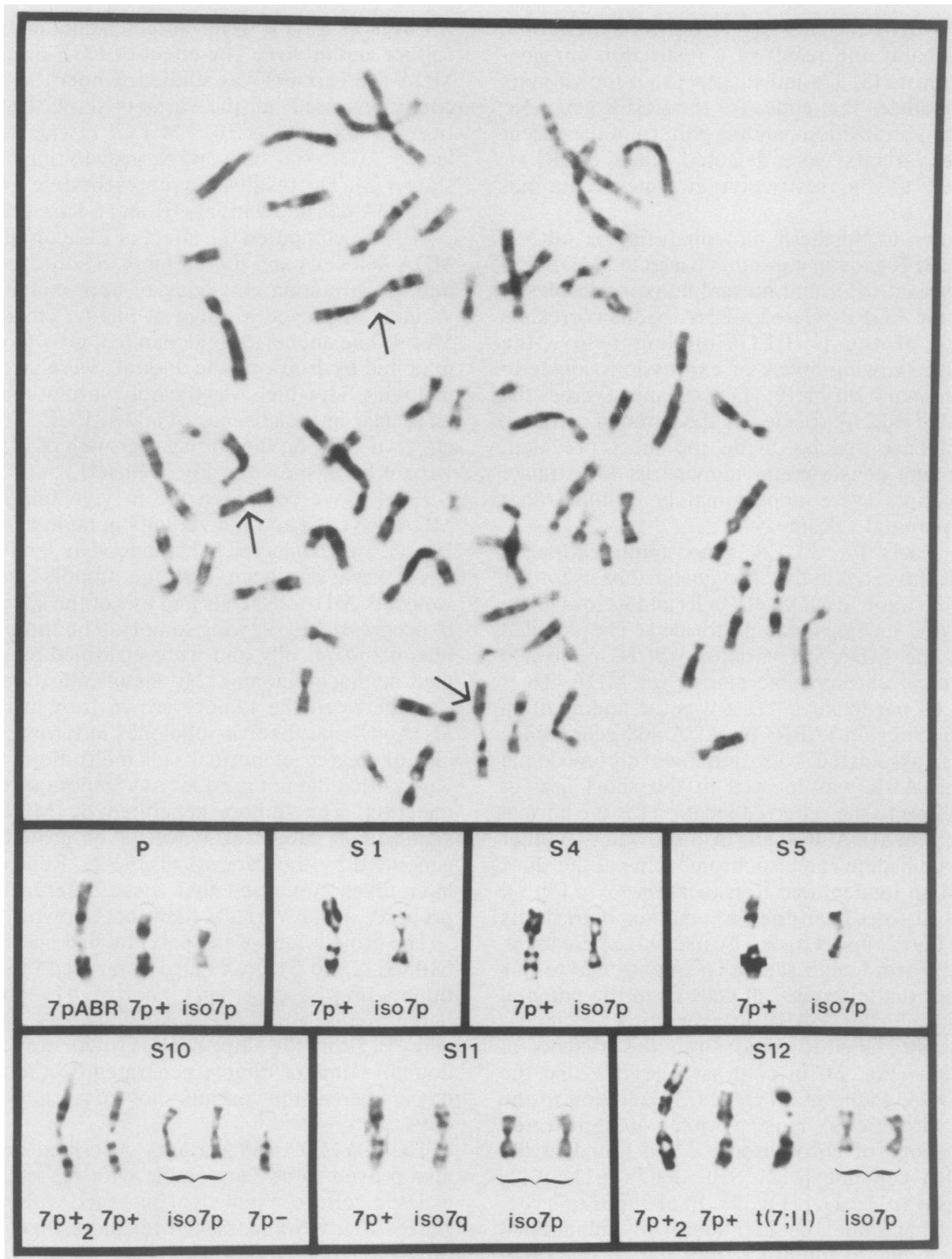

FIG. 2. Pictorial documentation of chromosome 7 alterations in the parental MDA-468 cell line (P) and six variants (S1, S4, S5, S10, S11, and S12). Top: G-banded mid-metaphase cell from the parental cell line MDA-468. The modal number of this line was 58, with several clonal structural alterations observed. The arrows indicate the three different structural alterations involving chromosome 7 . Bottom: Insets depict G-banded profile of the altered chromosome 7's from the parental cell line and each variant.

Kawamoto et al. (11) have studied variants derived from A431, another tumor cell line which has an amplified EGFR gene and is growth inhibited by EGF. Those variants had a wide variation in the number of EGFR. Generally, clones with a high number of EGFR (but not as high as the parental line) were still growth inhibited under the influence of EGF doses above $10^{-9} \mathrm{M}$, whereas clones with fewer receptors were resistant to that dose. We have concluded, therefore, that there is a quantitative relationship between EGFR and growth response, and when an optimum amount of EGFR is exceeded, growth inhibition results after exposure to EGF. Our results are consistent with this model, although the lack of variants with an intermediate number of EGFR did not allow us to investigate whether there is a threshold number of EGFR for the EGF-induced inhibition that occurs in MDA-468 cells.

Southern blot analysis with HindIII as the restriction enzyme (Fig. 1) suggests that the MDA-468 variants have lost one of the alleles that code for the EGFR gene. This is consistent with the karyological data, which show that chromosome 7, which harbors an ABR containing the amplified EGFR gene, has been lost in all the variants.

Although we have not yet performed in situ hybridization analysis of the EGFR gene in the variants, the intensity of the EGFR gene-related bands in the Southern blots of these variants clearly suggests that the ABR of chromosome 7 was 
the only location for the amplified EGFR gene. In A431 cells the amplified EGFR sequences have been found in two different marker chromosomes (17). The presence of the amplified EGFR gene in more than one location and the reported instability in the chromosome population of A431 cells (17) can explain the finding of EGF-resistant variants with a broad variation in the number of EGFR genes (15). This was not found in MDA-468 variants, and this further supports the 7pABR chromosome as the only location for the amplified EGFR sequences. Such a single localization of the amplified genes may account for the high frequency of variants detectable in the absence of mutagenesis.

EGF plays an important role in the proliferation of different types of cells, including cells from the breast epithelium $(2,22)$. It has been proposed that EGFR overexpression may confer a growth advantage under conditions of limiting EGF (5). The recently reported finding that a significant proportion of a very malignant type of human glioblastoma

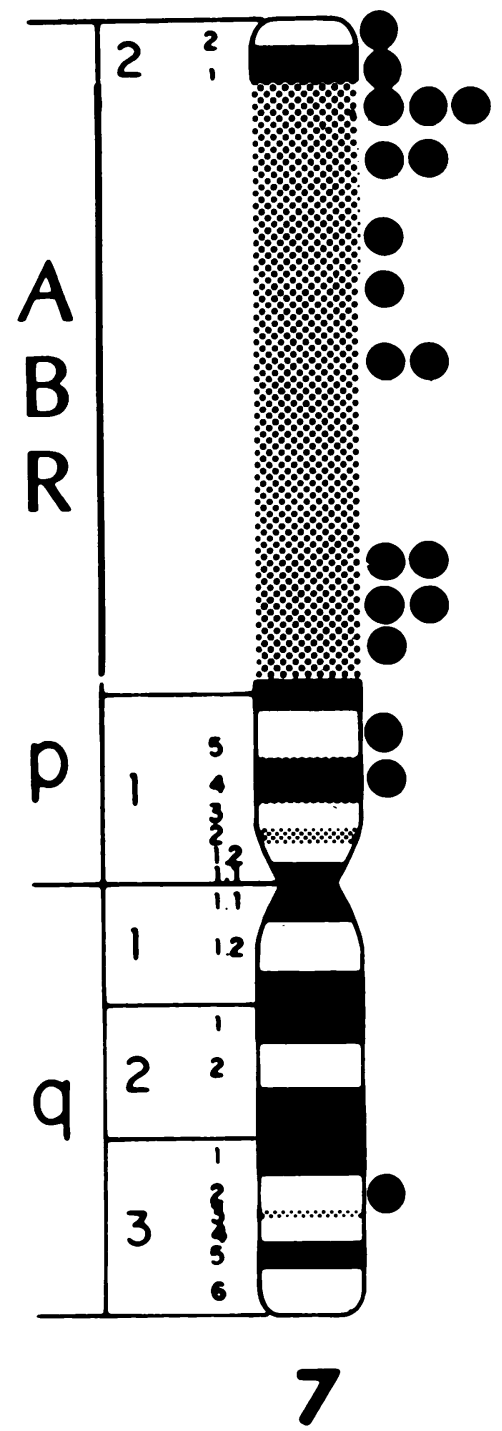

FIG. 3. In situ hybridization of the EGFR gene in MDA-468 cells. Schematic representation of G-banded mid-metaphase chromosome 7pABR. Stippling depicts the loci of the ABR. Dots depict autoradiographic grains localized to this marker following in situ hybridization with ${ }^{3} \mathrm{H}$-labeled cDNA encoding the EGFR (pE7).

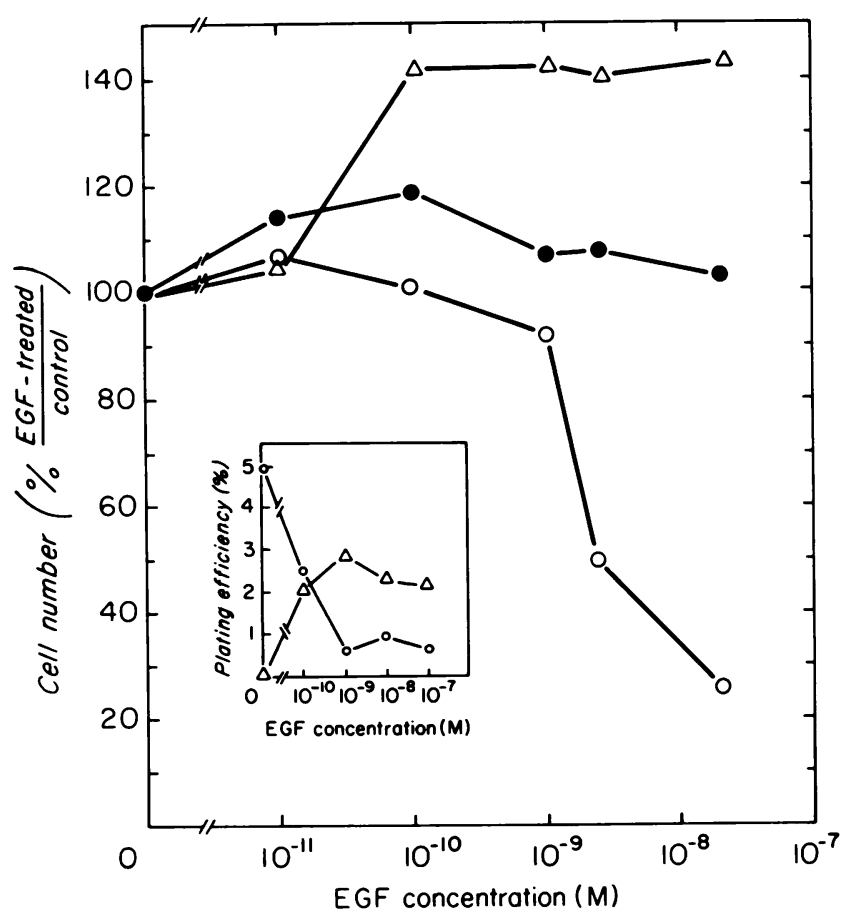

FIG. 4. Effect of EGF concentration on cell proliferation. A total of $10^{4}$ cells were plated in triplicate in $35-\mathrm{mm}$ plates and incubated at $37^{\circ} \mathrm{C}$ for 7 days. Points represent percent change in cell number for cells grown in various EGF-supplemented media compared with cells grown in control media. Symbols: $\mathrm{O}, \mathrm{MDA}-468 ;-\mathrm{S} 1 ; \triangle, \mathrm{S} 4$. Inset: Effect of EGF on growth in soft agar cultures. A total of $10^{4}$ cells were plated in triplicate in a two-layer system of agar and incubated at $37^{\circ} \mathrm{C}$ for 3 weeks. Points represent plating efficiency (colony definition, $\geq 60$ cells) for cells grown in various EGFsupplemented media. Symbols: $O$, MDA-468; $\triangle$, S4.

show EGFR gene amplifications (14) also suggests that elevated receptor expression could be involved in the growth advantage underlying tumor progression. To test this hypothesis, we compared tumorigenicity in nude mice after the injection of MDA-468 cells and the six clonal variants. Our results show (Table 2) that the parental cell line was able to generate significantly larger tumors than the nonamplified variants. The basis for this size difference at 9 weeks of growth is primarily due to a growth rate advantage, since doubling time for the parental cells was significantly shorter (Fig. 5). Although we cannot discard the possibility that differences other than the lack of EGFR amplification are responsible for the slower growth of the tumors generated by the variants (e.g., immunogenicity, other growth factorrelated receptors), it is highly unlikely that common differ-

TABLE 2. Weight of tumors generated by MDA-468 cells and variants in nude mice

\begin{tabular}{|c|c|}
\hline Cell line & $\begin{array}{c}\text { Mean } \\
\text { tumor wt } \\
(\mathrm{mg}) \pm \mathrm{SE}\end{array}$ \\
\hline $\begin{array}{l}\text { MDA-468 } \\
\text { S1 } \ldots \ldots \\
\text { S4 } \ldots \ldots \\
\text { S5 } \ldots \ldots \\
\text { S10 } \ldots \ldots \\
\text { S11 } \ldots \ldots \\
\text { S12 } \ldots \ldots\end{array}$ & 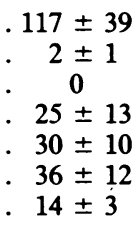 \\
\hline
\end{tabular}




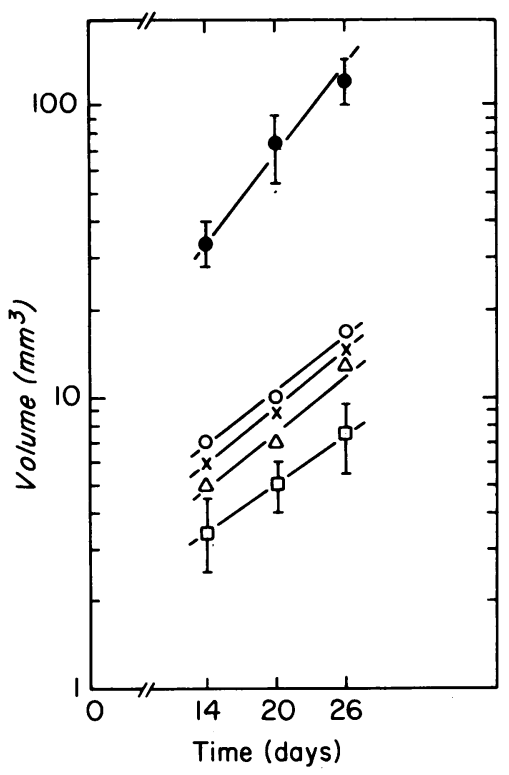

FIG. 5. Time course of tumor growth. Each point is the mean value for seven tumors grown in different mice. Standard errors for S5, S10, and S12 are not shown for reasons of clarity, but they did not exceed $20 \%$ of the mean value. Symbols: - MDA-468; $\times$, S5; $\triangle, \mathrm{S} 10 ; \square, \mathrm{S} 11 ; \mathrm{O}, \mathrm{S} 12$

ences other than lack of EGTR gene amplification are present in the six independently isolated clones. The data may therefore reflect a progression-related growth advantage provided to the tumor by amplification of the EGFR gene.

Despite the fact that five of the six variants were able to produce tumors in nude mice, a causative role cannot be excluded for EGFR amplification in the generation of the original MDA-468 tumor. Growth of the tumor in vivo or propagation of the cell line in culture might have elicited secondary changes affecting other transformation-related genes.

It is of interest that the only variant that did not generate tumors in nude mice (S4) was also the only one that did not grow in soft agar without the addition of EGF. After the addition of EGF, however, its anchorage-independent growth was dramatically stimulated (Fig. 4, inset). On the other hand there was no significant difference in proliferative behavior on plastic between the S4 cells and the other variants. The differential effect of EGF on the growth of cells in anchorage-independent conditions as opposed to anchorage-dependent conditions has also been noted for other cell types (13). The S4 variant may provide a model system for studying the molecular basis for anchorage-independent growth of epithelial cells.

\section{ACKNOWLEDGMENTS}

We are grateful to Rose Pullano and Barbara Choo for excellent technical assistance and Avril Jones for preparation of the manuscript.

Jorge Filmus and Michael Pollak were fellows of the Terry Fox Postdoctoral Programme of the National Cancer Institute of Canada. J. M. Trent is a scholar of the Leukemia Society of America. The work was supported by grants from the Medical Research Council of Canada and National Cancer Institute of Canada and by U.S. Public Health Service grants CA-29476, CA-12094, and CA-29526 awarded by the National Cancer Institute.

\section{LITERATURE CITED}

1. Biedler, J., and H. Riehm. 1970. Cellular resistance to actinomycin D in Chinese hamster cells in vitro: crossresistance, radioautographic and cytogenetic studies. Cancer Res. 30:1174-1184.

2. Carpenter, G., and S. Cohen. 1979. Epidermal growth factor. Annu. Rev. Biochem. 48:193-216.

3. Filmus, J., M. N. Pollak, R. Cailleau, and R. N. Buick. 1985. MDA-468, a human breast cancer cell line with a high number of epidermal growth factor (EGF) receptor, has an amplified EGF receptor gene and is growth inhibited by EGF. Biochem. Biophys. Res. Commun. 128:898-905.

4. Filmus, J., M. N. Pollak, J. G. Cairncross, and R. N. Buick. 1985. Amplified, overexpressed and rearranged epidermal growth factor receptor gene in a human astrocytoma cell line. Biochem. Biophys. Res. Commun. 131:207-215.

5. Gill, G. N., P. J. Bertics, D. M. Thompson, W. Weber, and C. Cochet. 1985. Structure and regulation of the epidermal growth factor receptor, p. 11-18. In J. Feramisco, B. Ozanne, and C. Stiles (ed.), Cancer cells, vol. 3. Cold Spring Harbor Laboratory, Cold Spring Harbor, N.Y.

6. Gill, G. N., and C. S. Lazar. 1981. Increased phosphotyrosine content and inhibition of proliferation in EGF-treated A431 cells. Nature (London) 293:305-307.

7. Gusella, J. F., C. Keys, B. A. Varsanyi, F. T. Kao, C. Jones, T. T. Puck, and O. Housman. 1979. Precise localization of human $\beta$-globin gene complex on chromosome 11. Proc. Natl. Acad. Sci. USA 76:5239-5243.

8. Gusterson, B., G. Cowley, J. McIlhinney, B. Ozanne, C. Fisher, and B. Reeves. 1985. Evidence for increased epidermal growth factor receptors in human sarcomas. Int. J. Cancer 36:689693.

9. Hunts, J., M. Veda, S. Ozawa, O. Abe, I. Pastan, and N. Shimizu. 1985. Hyperproduction and gene amplification of the epidermal growth factor receptor in squamous cell carcinomas. Jpn. J. Cancer Res. (Gann) 76:663-666.

10. International Committee for Cytogenetic Nomenclature. 1985. International system for human cytogenetic nomenclature. Cytogenet. Cell Genet. 21:1-117.

11. Kawamoto, T., J. Mendelsohn, A. Le, G. H. Sato, C. S. Lazar, and G. N. Gill. 1984. Relation of epidermal growth factor receptor concentration to growth of human epidermoid carcinoma A431 cells. J. Biol. Chem. 259:7761-7766.

12. Kudlow, J. E., C.-Y. M. Cheung, and J. D. Bjorge. 1986. Epidermal growth factor stimulates the synthesis of its own receptor in a human breast cancer cell line. J. Biol. Chem. 261:4134-4138.

13. La Rocca, P. J., and J. G. Rheinwald. 1985. Anchorage independent growth of normal human mesothelial cells. A sensitive bioassay for EGF which discloses the absence of this factor in fetal calf serum. In Vitro 21:67-72.

14. Libermann, T. A., H. R. Nusbaum, N. Razon, R. Kris, I. Lax, H. Soret, N. Whitle, M. D. Waterfield, A. Ullrich, and J. Schlessinger. 1985. Amplification, enhanced expression and possible rearrangement of EGF receptor gene in primary human brain tumours of glial origin. Nature (London) 313:144-147.

15. Lin, C. R., W. S. Chen, W. Kruiger, L. S. Stolarsky, W. Weber, R. M. Evans, I. M. Verma, G. N. Gill, and M. G. Rosenfeld. 1984. Expression cloning of human EGF receptor complementary DNA: gene amplification and three related messenger RNA products in A431 cells. Science 224:843-848.

16. Mayes, E. L. V., and M. D. Waterfield. 1984. Biosynthesis of the epidermal growth factor receptor in A431 cells. EMBO J. 3:531-537.

17. Merlino, G. T., S. Ishii, J. Whang-Peng, T. Knutsen, Y.-H. Xu, A. J. L. Clark, R. H. Stratton, R. K. Wilson, D. P. Ma, B. A. Roe, J. H. Hunts, N. Shimizu, and I. Pastan. 1985. Structure and localization of genes encoding aberrant and normal epidermal growth factor receptor RNAs from A431 human carcinoma cells. Mol. Cell. Biol. 5:1722-1734.

18. Merlino, G. T., Y.-H. Xu, S. Ishii, A. J. L. Clark, K. Semba, K. Toyoshima, T. Yamamoto, and I. Pastan. 1984. Amplification and enhanced expression of the epidermal growth factor recep- 
tor gene in A-431 human carcinoma cells. Science 224:417-419.

19. Pathak, S., M. J. Siciliano, R. Cailleau, C. L. Wiseman, and T. L. Hsu. 1979. A human breast adenocarcinoma with chromosome and isoenzyme markers similar to those of the HeLa line. J. Natl. Cancer Inst. 62:263-271.

20. Rigby, P. W. J., M. Dieckmann, C. Rhodes, and P. Berg. 1977. Labelling deoxyribonucleic acid to high specific activity in vitro by nick translation with DNA polymerase I. J. Mol. Biol. 113:237-251.

21. Southern, E. M. 1975 . Detection of specific sequences among DNA fragments separated by gel electrophoresis. J. Mol. Biol. 98:503-517.

22. Taketani, Y., and T. Oka. 1983. Biological action of epidermal growth factor and its functional receptors in normal mammary epithelial cells. Proc. Natl. Acad. Sci. USA 80:2647-2650.
23. Thomas, P. S. 1980 . Hybridization of denatured RNA and small DNA fragments transferred to nitrocellulose. Proc. Natl. Acad. Sci. USA 77:5201-5205.

24. Trent, J. M. 1980. Protocols of procedures and techniques in chromosome analysis of tumor stem cell cultures in soft agar, $p$. 345-349. In S. E. Salmon (ed.), Cloning of human tumor stem cells. Alan R. Liss Inc., New York.

25. Trent, J., S. Olsen, and R. Lawn. 1982. Chromosomal localization of human leukocyte, fibroblast and immune interferon genes by means of in situ hybridization. Proc. Natl. Acad. Sci. USA 79:7809-7813.

26. Xu, Y.-H., N. Richert, S. Ito, G. T. Merlino, and I. Pastan. 1984. Characterization of epidermal growth factor receptor gene expression in malignant and normal human cell lines. Proc. Natl. Acad. Sci. USA 81:7308-7312. 